\title{
A Universidade e o Estado Novo: De "corporação orgânica" do regime a território de dissidência social
}

The University and the 'New State': From the Regime's 'Organic Corporation' to the Territory of Social Dissent

L'Université et l'“Etat Nouveau": de la corporation organique du régime au territoire de dissidence sociale

\section{Álvaro Garrido}

\section{OpenEdition}

\section{Journals}

Edição electrónica

URL: http://journals.openedition.org/rccs/656

DOI: $10.4000 /$ rccs.656

ISSN: 2182-7435

\section{Editora}

Centro de Estudos Sociais da Universidade de Coimbra

Edição impressa

Data de publição: 1 Junho 2008

Paginação: 133-153

ISSN: 0254-1106

Refêrencia eletrónica

Álvaro Garrido, "A Universidade e o Estado Novo: De "corporação orgânica" do regime a território de dissidência social », Revista Crítica de Ciências Sociais [Online], 81 | 2008, colocado online no dia 01 outubro 2012, criado a 30 abril 2019. URL : http://journals.openedition.org/rccs/656 ; DOI : 10.4000/ rccs. 656 


\section{ÁLVARO GARRIDO}

\section{A Universidade e o Estado Novo: De "corporação orgânica" do regime a território de dissidência social}

O presente ensaio procura relacionar os discursos do Estado Novo sobre a Universidade e acerca dos organismos associativos estudantis (a reprodução) com as estratégias de sobrevivência e imaginação do próprio movimento de estudantes (a contestação). Como ponto de partida para uma análise dos movimentos estudantis entre o termo da Segunda Guerra Mundial e meados da década de sessenta do século XX tomam-se os estereótipos salazaristas da Universidade enquanto "corporação orgânica" do regime ditatorial e a matriz legal das associações de estudantes como "sindicatos corporativos" inibidos de expressar quaisquer conotações classistas. O texto revisita anteriores discussões relativas à emergência do "sindicalismo estudantil" na primavera de 1962, procurando aferir por que modos e razões a Universidade se constitui em palco relevante de dissidência do regime, acompanhando as sucessivas crise que a ditadura enfrenta de 1958 em diante.

Emancipar os homens, treinando-os no uso do proceder autónomo, - autodisciplinado, racional, humanista: tal é, com efeito, o verdadeiro objectivo de quem educa os jovens. Para os que tomaram consciência de ser de facto assim (e só não tomam consciência de ser de facto assim os que nada compreendem da grande questão pedagógica) todas as intervenções das autoridades do Estado nas associações formados pela Grei estudantil parecerão de reprovar e de rejeitar de todo, como anti-pedagógicas no mais alto grau.

SÉRGIO, 1957: 9

Por meio desta proclamação, proferida no rescaldo do movimento de estudantes gerado pelo controverso Decreto-Lei $\mathrm{n}^{\circ} 40$ 900, de 12 de Dezembro de 1956, António Sérgio tomava posição cívica perante a mais recente tentativa do Estado Novo de cercear a autonomia das associações estudantis. Em simultâneo, reafirmava o seu idealismo crítico, de raiz kantiana, sobre a "grande questão pedagógica". 
Ainda que historicizada e reportada ao despotismo legislativo da ditadura, a reflexão da mais respeitável figura do "socialismo democrático" 1 que se destacou nas oposições exprime uma sólida filosofia da educação. O axioma segundo o qual, "da escola primária à superior, deve haver um treino de práticas sociais fundado na ideia da autonomia dos jovens”, será menos tributário do "socialista libertário" com que Sérgio se anuncia a abrir o seu sétimo caderno antológico do que um manifesto da paideia republicana. Fiel à matriz positivista, o discurso metapolítico de António Sérgio teria por fim modernizar, no longo prazo, o pensamento e a mentalidade cultural da intelligentsia portuguesa.

O ensaio sociológico do antigo seareiro pode ainda ser lido de outros modos. Então com 74 anos de idade, Sérgio era dos primeiros intelectuais portugueses a entender a emergência da juventude como categoria social autónoma. Não por acaso, o largo comentário crítico que dedicou à acção persecutória do Governo em matéria de regulamentos sobre a vida associativa estudantil não foi menos incisivo nos reparos aos "rapazes de Coimbra". O provincianismo de que arguiu os estudantes rebelados da Alma Mater resultaria, em seu entender, das "vistas curtas" que o expressivo grupo e os seus cabecilhas teriam dado mostras ao recusarem argumentos comuns de juvenilidade no trato conflitual com as autoridades (Sérgio, 1957: 33). Marcadamente “corporativo", pouco aberto a dinâmicas federativas e muito preso às singularidades do meio estudantil de Coimbra - interpretação que a análise historiográfica do movimento de 1956-57 nem sempre confirma ${ }^{2}$-, o protesto estudantil foi, pela primeira vez na sua trajectória intermitente, pontuado de reivindicações de juvenilidade. ${ }^{3}$

Por finais de Cinquenta, o desencanto dos jovens universitários começa a ser comum e expresso, com as necessárias subtilezas, em diversos lugares de escrita: em memorandos redigidos por associações de estudantes, em comunicados estudantis e no jornal Via Latina, da Associação Académica de Coimbra, são comuns as expressões de frustração dos escolares quanto às possibilidades de realização da sua condição juvenil no espaço

\footnotetext{
${ }^{1}$ A expressão é de Hermínio Martins, vertida no seu velho, mas vivo ensaio sobre as tipologias da oposição ao Estado Novo na alvorada marcelista (1998: 53-68).

2 Cf. Garrido, 1996: 53-76; Fontes, 1991: 17-42; Lopes, 1992: 170-189. Este último estudo ajuda a perceber de que modo o movimento dos estudantes de Coimbra teve como móbil, além das razões mais conhecidas, a defesa da participação da Associação Académica no desporto federado, em especial no futebol.

3 Antes de 1956, alguns discursos houve no movimento estudantil que também exprimiram frustração pelo facto de o regime ditatorial impedir uma vivência livre da condição juvenil. Boa parte dessas expressões foram formuladas por elementos do MUD juvenil após o termo da Segunda Guerra Mundial; tiveram um acento político e não tanto sócio-cultural (Vilaça, 1998: 17-42).
} 
associativo universitário (Torgal, 1999: 229ss.; Garrido, 1996: 90ss.). Tal sufoco e mordaça exprimiam-se na chamada legislação sobre as "actividades circum-escolares dos estudantes" que o Governo de Salazar se vinha preparando para impor no sentido de reprimir a progressão das associações para lógicas e práticas sindicais. Tal como em momentos anteriores, era previsível que o esmero legislativo da elite governamental acabasse por despertar o movimento estudantil e que, a ser assim, a vontade de prevenir a "agitação dos rapazes" acabasse por revelar singulares efeitos perversos. Como efectivamente aconteceu.

Passando à memória social das lutas estudantis como um generoso momento de defesa do direito à autonomia associativa dos estudantes, $\mathrm{o}$ movimento de 1956-57 foi também um extraordinário percutor de consciências. A conjugação dos efeitos mentais e cívicos da luta contra o "40 900" com a explosão popular de 1958 gerada pela campanha eleitoral do general Humberto Delgado criou uma plataforma estudantil disponível para a acção colectiva, disposta a unir-se em defesa de liberdades públicas de sentido primário dentro das Escolas. Aos apelos cívico e político de alguns juntava-se a frustração dos que reclamavam um "suplemento de alma" para os seus cursos e para a própria vida circum-escolar. Assim se exprimia a desilusão de quantos concluíam que aquela Universidade não lhes proporcionava uma formação humana plural nem lhes consentia que experimentassem livremente a "irresponsabilidade provisória" 4 que tipifica os comportamentos juvenis.

Muito além das vicissitudes da luta estudantil que se travou nas três universidades portuguesas em 1956-57, o ensaio de António Sérgio acabava por questionar toda a organização da Universidade portuguesa e por colocar em questão o principal problema com que o Estado Novo se debatia naquele período; talvez o "grande medo" que Salazar sempre reprimira nos meios estudantis universitários, o sindicalismo estudantil.

O presente ensaio, necessariamente contido nos seus intentos de discussão, procura debater, em vários planos, essa tensão original e os seus principais desenlaces:

1) Problematizar o confronto entre os estereótipos salazaristas da Universidade enquanto "corporação orgânica do regime" e das associações de estudantes como "sindicatos corporativos" com escassos poderes de representação e esterilizados de conotações classistas;

${ }^{4}$ Usado em diversos registos da sociologia da juventude, o conceito foi formulado pelo sociólogo Charles Bidwell. 
2) Pôr em evidência a crescente incompatibilidade entre os arquétipos legais e a vida associativa estudantil, com especial relevo para o período post-bélico e anterior à "grande crise" de 1961-62;

3) Revisitar a nossa discussão anterior, relativa à emergência do sindicalismo estudantil na Primavera de 1962, e procurar aferir por que modos e razões a Universidade se constitui em palco principal de dissidência do regime, acompanhando as sucessivas crises que a ditadura enfrenta de 1958 em diante. ${ }^{5}$

Para estas perguntas axiais, ensaiaremos respostas provisórias, construídas sobre intuições explicativas. A Universidade que evocamos nunca foi a nossa; o campo semântico em que nos movemos não nos pertence. O conhecimento que neste e em pretéritos ensaios construímos sobre a Universidade salazarista e os seus abalos primaveris protagonizados por movimentos sociais de estudantes alimenta-se de perguntas impressivas e consistentes, de investigações nossas e em boa parte de estudos de especialistas na matéria, entretanto renovados. ${ }^{6}$

A título de prevenção, importa advertir para os múltiplos ardis que a memória social das lutas estudantis emprestou à história desses movimentos. A primeira - talvez a mais significativa - será a representação dos dirigentes estudantis como "vanguardas revolucionárias". Se é certo que a rebeldia dos estudantes universitários precedeu e acompanhou as principais crises políticas do Estado Novo português, tal relação não autoriza o privilégio de uma visão filogenética do movimento estudantil, como se os picos de revoltas e greves se inscrevessem numa linearidade finalista, necessariamente consumada no derrube do regime, em 1974. A fim de evitar as insuficiências deste esquema mental, o nosso ensaio procura relacio-

\footnotetext{
${ }^{5}$ Aprofundámos esta discussão em Garrido, 1995, e 1996: 119-198. A síntese que aqui se publica actualiza ambos os textos.

${ }^{6}$ Não cabe aqui arrolar todos os estudos historiográficos e sociológicos relativos à Universidade e aos movimentos estudantis durante o Estado Novo. Sobre o primeiro tema, a investigação mais profunda e sistemática, já citada e relativa à Universidade de Coimbra, pertence a Luís Reis Torgal. Sobre os movimentos estudantis, além do nosso estudo sobre a "crise académica de 62" (resultante de uma tese de Mestrado igualmente centrada na Academia de Coimbra), constituem referências os livros de Nuno Caiado (1990) e de Celso Cruzeiro (1989). Num ensaio que podemos classificar de sociologia histórica da juventude (relativo aos anos sessenta em Portugal), realce para o excelente livro de Rui Bebiano, O poder da imaginação (2003). De publicação ainda mais recente, justificam realce os seguintes livros, ambos centrados nos movimentos de estudantes de Coimbra, respectivamente um projecto colectivo de investigação e uma dissertação de mestrado dedicada ao período "marcelista": Elísio Estanque e Rui Bebiano, Do activismo à indiferença (2007); Miguel Cardina, A tradição da contestação (2008). O primeiro autor a construir interpretações históricas de movimentos estudantis contra a ditadura salazarista foi, porém, o sociólogo Rui Grácio. Dos seus artigos sobre o tema, destaquemos o principal: "Moral e política na Academia de Coimbra, crónica documental de uma polémica no dealbar dos anos sessenta” (1989).
} 
nar os discursos e práticas do Estado Novo sobre a Universidade e acerca dos organismos associativos estudantis (a reprodução) com as estratégias de sobrevivência do próprio movimento de estudantes (a contestação). No tempo histórico da ditadura salazarista, este segundo termo do binómio relacional tanto se expressou em movimentos sociais e acção colectiva, como noutras formas de resistência à tutela e repressão governamentais.

\section{O Estado Novo, a Universidade e o movimento associativo estudantil}

Finda a Segunda Guerra Mundial, cresceram nos meios universitários as esperanças de renovação e democratização do regime que a derrota dos fascismos fizera alimentar. Apesar da vaga exterior, exceptuando a acção de aparência legal do MUD Juvenil, em Lisboa, e os efeitos do "episódio Zenha" que se abriu em Coimbra em finais de 1944, o movimento associativo de estudantes permanecia severamente limitado nas suas possibilidades de crescimento e renovação pela legislação de 1932 e seus avatares. Através dela o Estado Novo erguera um dos seus pilares preventivos e constitutivos: tutelar a vida circum-escolar das instituições de ensino superior, impondo-lhes um modelo associativo unívoco, capaz de truncar a eventual progressão das associações de estudantes para lógicas sindicais, hostis ao arquétipo doutrinário da Universidade como "corporação orgânica de mestres e alunos". Antes mesmo de a ditadura se constitucionalizar, tendo presente a virulência das lutas estudantis do "reviralho", 7 Salazar cuidou de esterilizar as associações de estudantes.

Neste como noutros discursos legislativos, são mais numerosos os fins que se insinuam do que os explicitados. No par de decretos que até 1956 acabaria por regular a vida associativa estudantil, exprimem-se, porém, alguns propósitos claros: instituem-se relações de dependência orgânica das associações de estudantes (AE) relativamente aos órgãos de governo das universidades (Senado, Reitor e Conselhos Escolares); inibem-se as possibilidades de co-gestão universitária; confina-se o perfil das $\mathrm{AE}$ a uma prática assistencialista, de mera prestação de serviços; limita-se-lhes a representatividade de modo a impedir a progressão sindical do movimento associativo. Embora precoce, a inibição de quaisquer tendências dos estudantes portugueses para se filiarem nas "internacionais estudantis" também se presume na intenção do legislador. Ante este quadro legal hiper-preventivo, e porque a $\mathrm{AAC}$ tendia para uma representação monolítica dos estudantes, em rigor a velha Associação viveu sempre na ilegalidade.

\footnotetext{
7 Sobre as "crises estudantis" do período da Ditadura Militar (1926-1933), cf. Comissão do Livro Negro sobre o Regime Fascista (1983). Num registo historiográfico, cf. Faria, 1998.
} 
$\mathrm{Na}$ óptica dos doutrinadores, a versão portuguesa da "Universidade fascista" 8 reduziria os seus esforços de instrução e acentuaria a sua "missão educativa" nacionalista-conservadora. Uma "missão" capaz de vincular as escolas a uma ordem social construída sobre pilares há muito irreconciliados pelo "desvario republicano": a ética cristã, a moral católica e os valores patrióticos. A Universidade seria a expressão eloquente de um nacionalismo reconstruído, tradicionalista e imperial; baluarte institucional de um Estado "limitado pela lei e pela moral"; Universidade "organicista e não democrática".

Legitimada por estes dogmas, a Universidade de Salazar não seria a de Kant nem a de Humboldt. A primeira, de raiz iluminista, moldara-se pela ideia de Razão. A segunda, idealista, ordenara-se pela ideia de cultura e radicara no propósito oitocentista alemão de ligar tradição étnica e racionalidade estatal. ${ }^{10}$ À Universidade portuguesa herdada pelo Estado Novo, síntese pouco clara daqueles paradigmas, o ditador pouco acrescentou. Não terá ousado, sequer, refundá-la ou tão pouco criar uma "Universidade nova". Se, durante o salazarismo a Universidade continuou a ser a principal instituição pública de "cultura nacional", a elite ditatorial aditou-lhe uma missão educativa e formativa, de natureza instrumental e fins reprodutores: formar a classe dirigente da Nação. Tal vocação condicionava fortemente as relações da Universidade com a sociedade, como justificava todos os esforços governamentais para colocar a instituição universitária dentro do Estado.

Por razões históricas entretanto reelaboradas e, com certeza, por conjugar um certo "capital cultural" de valores tradicionais com a ideologia conservadora do Estado Novo, a Universidade de Coimbra foi declarada "Universidade do regime". Enquanto estudante de Coimbra, no Centro Académico de Democracia Cristã (CADC), Salazar entregara-se a militâncias de oposição ao laicismo da República e ajudara a afirmar o cato-

\footnotetext{
${ }^{8}$ Num congresso realizado em Saragoça em 1989, diversos investigadores europeus discutiram se, efectivamente, houve um modelo fascista de Universidade. As conclusões não foram unânimes, mas tenderam a considerar que o país onde o ideal fascista de Universidade (entendido em sentido lato) mais se concretizou foi a Alemanha nacional-socialista. Nos demais "fascismos" não chegou a existir uma "Universidade nova" e nitidamente fascista, mas um forte controlo governamental da instituição universitária por parte do partido único e das suas oligarquias. No caso nazi, por exemplo, sublinha-se que, quando o NSDAP chegou ao poder, em 1933, já dominava o movimento estudantil desde 1930, ao passo que, nesta mesma data, seriam poucos ou nenhuns os professores universitários filiados no Partido. Cf. Carreras Ares, 1991: 13-27.

9 O problema universitário em Portugal, Lisboa, Editorial Vanguarda, 1934. Documento citado em Torgal, 1999: 89.

${ }^{10}$ Para um excelente ensaio de sociologia histórica sobre a evolução das matrizes culturais da "Universidade ocidental", cf. Readings, 2003.
} 
licismo social-corporativo que havia de constituir a medula ideológica do Estado Novo. Feito chefe do Governo em 1932, Salazar pensa a Universidade de Coimbra de onde viera como uma espécie de "reserva moral da Nação", um "farol de virtudes patrióticas" cuja missão cultural só podia concretizar-se se convertida em "corporação orgânica do regime". Assim definida e assim exaltada, a missão política da Universidade de Coimbra não admitiria outro perfil que não o de uma "universidade clássica" ou "humanístico-científica". ${ }^{11}$

Dando expressão a tal modelo institucional (também cultural e ideológico), a Universidade de Coimbra não conheceu quaisquer alterações de estrutura curricular até às décadas de sessenta e de setenta. Extinta a Escola Normal Superior de Coimbra em 1930 e despromovida a Faculdade de Farmácia à categoria de Escola em 1928, a Universidade de Coimbra foi re-instituída como "universidade clássica, centro de alta cultura e de investigação científica”. Na sua composição quadrivial - até 1968, compuseram-na as faculdades de Letras, Direito, Medicina e Ciências não teve lugar para o ensino técnico ou tecnológico que, em 1930, Salazar e o ministro da Instrução Pública, Gustavo Cordeiro Ramos, decidiram reunir na Universidade Técnica de Lisboa, ${ }^{12}$ dando certa continuidade à "reforma republicana" de 1911.

O preceito constitucional de 1933 deixava perceber que a Universidade do Estado Novo seria uma pragmática adaptação de diversas heranças. Conforme o artigo $17^{\circ}$ da Constituição, as Universidades portuguesas seriam "organismos corporativos de carácter cultural” cujo perfil orgânico o Estado Novo presumia reabilitar da história. A Universidade fora precedida pelos "Estudos Gerais" criados por D. Dinis, uma instituição corporativa de mestres e alunos. Alegadamente proscrito pela "Universidade liberal”, o espírito da Universitas Magistrorum et Scholarium foi evocado e exaltado sempre que, exprimindo lógicas polarizadas e sindicais, os alunos (estudantes) se rebelaram contra os mestres (professores) que o "Governo da Nação" investira de funções no governo da Universidade.

Adiante do discurso de exaltação orgânica da Universidade caminharam a prática e os instrumentos repressivos capazes de garantir que o modelo se cumprisse sem sobressaltos e dissidências de maior - da parte dos "rapazes" ou dos próprios docentes. A fim de prevenir os desvios, o

${ }_{11}$ Torgal, 2000: 559. Para uma análise detida e profunda das relações entre a Universidade de Coimbra e o Estado Novo entre 1926 e 1961, veja-se Torgal, 1991.

${ }^{12}$ Decreto n$^{\circ} 19$ 081, de 2 de Dezembro de 1930. 
Decreto $^{\circ} 25$ 317, de 13 de Maio de 1935, abrigava a possibilidade de demissão de quaisquer funcionários públicos que contrariassem o "espírito da Constituição corporativa”. Antes e depois da Guerra, o Governo faria "uso exemplar" desse largo chapéu repressivo impondo a demissão administrativa de alguns professores de Coimbra: Sílvio Lima e Aurélio Quintanilha, em 1935, Mário Silva em 1947.

À revelia de certas afirmações de princípio que sugeriam a salvaguarda dos valores da autonomia universitária e da liberdade de ensinar e de aprender, o Estado Novo acabou por instituir, de maneira formal e fáctica, uma série de mecanismos de inibição das liberdades nos campos universitário e circum-escolar. O testemunho insuspeito de Adriano Moreira recorda-nos alguns deles: a informação do que se ia passando nas universidades era sujeita ao crivo da Censura; o condicionamento político do acesso à carreira docente universitária e da própria investigação foram realidades bem sentidas, com danos morais e pessoais para os visados; a autonomia dos estabelecimentos de ensino foi limitada pelo princípio da nomeação governamental das autoridades académicas; a exclusão dos estudantes dos órgãos de governo das universidades foi uma prática comum e persistente (Moreira, 2000: 571).

Mais relevantes e visíveis do que os esforços de hiper-regulação da vida associativa estudantil foram as tentativas de desenho de uma política oficial de juventude: da "mocidade universitária", em primeiro lugar, e da "mocidade portuguesa" num segundo momento. A ordem de prioridades não foi, com certeza, arbitrária. $\mathrm{Na}$ base da política totalizante, de asfixia ideológica e cultural da Universidade, estariam medidas destinadas a instituí-la e a celebrá-la como corporação orgânica do regime ditatorial. Segundo o tipo-ideal doutrinário, a Universidade salazarista seria o alfobre das elites dirigentes da Nação; um espaço de harmoniosa convivência entre mestres e alunos; uma instituição destinada à "pesquisa desinteressada de novos conhecimentos literários, artísticos ou de investigação científica", bem como à divulgação do património intelectual. Nela se cumpriria o ideal de "educação nacional" que, em 1936, deu nome ao ministério confiado por Salazar a Carneiro Pacheco.

O enquadramento da "mocidade" surgiu na sequência directa da reorganização do Ministério da Instrução Pública. ${ }^{13}$ Tal como nos demais regimes autoritários e totalitários da Europa de entre as guerras, a Universidade foi o campo favorito das políticas oficiais de juventude. Prosseguindo objectivos de mobilização, arregimentação, de enquadramento

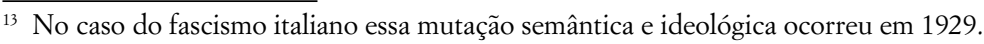


e integração (Garrido, 1998), a política de juventude do Estado Novo supunha estratégias de dominação e fortalecimento do regime capazes de dissuadir a emergência de culturas juvenis "privatizadas" ou estranhas à "ordem social".

Apesar das similitudes do modelo e da própria organização interna da milícia, a criação da Mocidade Portuguesa evidencia diferenças relativamente ao fascismo italiano e ao nacional-socialismo alemão. Num e noutro regime totalitário, a criação das respectivas organizações oficiais de juventude foi parte da estratégia de tomada do poder dos Partidos Nacional Fascista e Nazi. No caso português, o impulso de criação da Mocidade é uma iniciativa de membros da União Nacional, mas não é obra do partido único do Estado Novo. Na ditadura salazarista as organizações para-militares de enquadramento juvenil e civil (MP e Legião Portuguesa) não são pressupostos de edificação do regime, mas apenas parceiros do projecto de durabilidade do próprio "sistema" político e social. ${ }^{14}$

Em Novembro de 1936, com a Guerra Civil de Espanha sem desfecho à vista, os estudantes de Coimbra vêem severamente limitada a sua autonomia associativa: é impedida a representação discente no Senado e na Assembleia Geral da Universidade; são suspensas as eleições para a Associação Académica e, de imediato, nomeadas comissões administrativas de insuspeita ortodoxia. Previsivelmente, a punição governamental infligida aos "rapazes de Coimbra" abriria caminho a polarizações classistas dentro da Universidade. Contrariando as intenções do Governo ditatorial e o estereótipo legal imposto às associações...

Abria-se um longo ciclo de paralisia do movimento associativo estudantil e, conforme o desejo de Salazar, um período de franca colaboração da velha Universidade com o regime ditatorial. Fora das muralhas universitárias, o Estado Novo parecia realmente forte, embora ameaçado de Espanha. Reprimida a oposição "reviralhista" e volvida a memória das violentas greves estudantis de 1928, 1930 e 1931, a histeria antivermelha da direita radical alimentou uma certa mística de combate pelo regime. A Universidade de Coimbra tornara-se dócil e obediente, longe das acesas divisórias entre republicanos e integralistas que haviam marcado os tempos conturbados da Ditadura Militar. Para irritação de uns poucos estudantes, limitados pelo silêncio cúmplice da sua velha e controlada Associação, os órgãos universitários não tomaram posição contra as inibições forçadas da liberdade associativa dos escolares (Torgal, 1999: 95).

$\overline{14}$ Procedemos a este exame num artigo anterior, já citado (Garrido, 1998: 167-169). 
Até ao termo da Segunda Guerra Mundial, a Universidade de Coimbra viveu num "ambiente nacionalista e anticomunista", reprimida e vigiada, com escassas hipóteses de afirmação de quaisquer culturas de oposição (ibid.: 115). A convite do Senado, da Reitoria e da própria Associação Académica, vários ministros do regime vieram a Coimbra propagandear as virtudes do "Estado corporativo". Contrariando a herança de laicização republicana dos rituais académicos, a Universidade revigorou tradições de solenização do conhecimento, recolocou o sagrado em diversos cerimoniais (ibid:: 112ss.). Além de colaborar em diversos rituais nacionalistas e de legitimação do Estado Novo - aniversários da "Revolução Nacional" e outros -, a velha Universidade afirmou amiúde e de per si os principais valores do regime ditatorial: a "ordem", a "moral católica", a "civilização cristã e ocidental", o "Império". Nos anos trinta, multiplicam-se os doutoramentos honoris causa, mas é na década seguinte que tais consagrações, embora menos frequentes, tomam um significado político e ideológico mais evidente. $\mathrm{Na}$ Sala Grande dos Actos foram consagrados alguns lusófilos e certas figuras da Igreja Católica internacional. Por vontade de Salazar e do Cardeal Cerejeira, que se investe no papel de "padrinho" do "Generalíssimo", em 1949 teve lugar o doutoramento bonoris causa em Direito do chefe de Estado espanhol. ${ }^{15}$

Limitados por uma Universidade que fora colocada ao serviço do Estado e à mercê do Governo, os estudantes pouco se agitaram. Exceptuando uns poucos movimentos de protesto tradicionalista e a consciencialização política estimulada pelo MUD Juvenil - importante, mas circunscrita -, os estudantes viviam um quotidiano morno e lúbrico, ao ritmo das praxes e dos exames. ${ }^{16}$ A popularização simbólica da vivência estudantil e a infusão da Universidade num certo padrão de cultura rural e provinciana, inibiram o despertar das consciências para o problema das liberdades públicas e mesmo para a questão das autonomias universitária e associativa.

$\mathrm{Na}$ segunda metade dos anos cinquenta, com compreensível atraso começaram a chegar a Portugal os combates pelo reconhecimento da legitimidade da acção estudantil. De um apolitismo autêntico, mas também táctico e, pouco a pouco, feito um instrumento de expressão de posições políticas hostis ao regime ditatorial, passou-se à reivindicação de direitos e liberdades de âmbito mais geral e à formulação de ideias de transformação social a partir da Universidade.

\footnotetext{
15 Torgal, 1999: 145-148. O belo romance histórico e picaresco de Fernando Assis Pacheco, Trabalhos e Paixões de Benito Prada (1993), dedica à consagração de Franco pela Universidade de Coimbra algumas páginas mordazes.

${ }^{16}$ Cf. o testemunho de César Oliveira (1993: 21-25).
} 
Além deste estrangulamento e da ausência, por inibição superior, de condições de concretização da condição juvenil no espaço universitário português dos anos cinquenta e sessenta, a "Universidade salazarista" jamais quis (e pôde) assumir-se como alavanca de transformação social e, muito menos, de mudança política. A não ser através da dissidência e militância clandestinas de alguns dos seus estudantes e professores.

Por razões diversas e singulares, ao longo dos anos cinquenta o desencanto com a função "societal" da Universidade surge com insistência, expressa como formulação comum, nas "internacionais estudantis" - UIE ${ }^{17}$, COSEC $^{18}$ e outras. A tese paradigmática de Bourdieu e Passeron (1978), segundo a qual a Escola não estaria a transformar a sociedade, mas, pelo contrário, a reproduzir a estrutura social existente e a inibir a mobilidade social, encontra correspondência em vários autores portugueses, que apresentam argumentos semelhantes, baseados em análises consistentes e audazes. Mesmo em países com sistemas políticos democráticos, a frustração das esperanças igualitárias que dominaram os discursos e filosofias educativas do após-guerra caminhou de par com a emergência de uma sociologia crítica da educação, marcadamente pessimista sobre o papel da Escola e da Universidade na mudança e democratização das sociedades. Em Portugal, a expressão desse desapontamento foi tão vigorosa entre as elites da "oposição democrática" - veja-se o Programa para a Democratização da República de Janeiro de 1961, subscrito por eminentes personalidades anti-salazaristas, no qual, pela primeira vez, se reclamava a abertura do ensino - como em certas elites católicas conotadas com os sectores liberais do regime ditatorial - veja-se os escritos de Adérito Sedas Nunes e de Miller Guerra, entre outros estudos e ensaios. ${ }^{19}$

Embora alguns ministros da Educação Nacional de governos salazaristas do após-guerra - casos de Francisco Leite Pinto (1955-1956) e de Inocêncio Galvão Teles (1962-1968) - tenham ensaiado políticas educativas articuladas com programas de desenvolvimento económico visando a formação das "elites da Nação" e de "recursos humanos" qualificados para serem parte activa na execução dos Planos de Fomento, as três universidades do País não terão favorecido a mobilidade social. Confirmam-no estudos contemporâneos e o testemunho de Adriano Moreira, outra

\footnotetext{
${ }^{17}$ União Internacional dos Estudantes, com sede em Praga.

${ }_{18}$ Secretariado de Coordenação das Uniões Nacionais de Estudantes (segundo a designação inglesa). Tinha sede em Leiden, na Holanda.

19 Entre outros, recordemos alguns estudos de Adérito Sedas Nunes elaborados no Gabinete de Investigações Sociais e publicados nos primeiros números da revista Análise Social durante a segunda metade dos anos sessenta. Para uma lista completa, cf. Nunes, 2000, 395-397.
} 
vez precioso: "A vida universitária não era ameaçada pela explosão escolar, a aristocratização social dos estatutos era evidente, a distância entre professores e alunos era estrutural, o conservadorismo das percepções era dominante, a inovação condicionada”. Contudo, adverte o antigo ministro de Salazar, "a questão da democratização do ensino, à margem de qualquer processo exterior de democratização do regime, aflorou em várias oportunidades, designadamente por exigências simplesmente organizacionais, e por desafios da própria evolução controlada do modelo económico" (Moreira, 2000:571). Os números vertidos num célebre relatório da OCDE de 1964 continuam a ser contundentes e quase dispensam comentário: "De cada 100 alunos que frequentam a $4^{\mathrm{a}}$ classe de instrução primária, 70 passam o seu exame, só 18 entram no ensino secundário, cinco terminam o ano académico, e apenas dois obtêm um grau universitário" (ibid.: 571).

Neste apertado sistema, o condicionamento da opção liceal foi o instrumento mais eficaz para travar a "democratização do acesso" à Universidade. Sem embargo da abertura controlada de ambos os sistemas - de recordar que a bifurcação entre os liceus, enquanto antecâmaras das universidades, e as escolas técnicas, como instituições terminais de educação, sempre se manteve um processo de selecção social eficaz -, não restam dúvidas de que os sistemas secundário e universitário foram orientados para a "concessão de um estatuto genérico de elite" (Martins, 1998: 122). Tal engenharia social terá sido causa e efeito de um fenómeno mais vasto que as políticas educativas do salazarismo jamais quiseram contrariar: a fraqueza da classe média fez com que a Universidade nunca tivesse perdido o monopólio da formação das elites. Este estrangulamento prévio e estrutural permitiu à Universidade cumprir os seus fins de selectividade social; enquistou-a numa pedagogia de dominância escolástica que fez dela um poderoso agente de reprodução social e de imobilismo cultural.

Embora conhecida e aceite, esta interpretação não resiste a toda a prova. Não poucas investigações e testemunhos vêem na "natureza dominantemente burguesa" da Universidade salazarista uma limitação e uma força. A acelerada urbanização e terciarização que a sociedade portuguesa conheceu entre os anos cinquenta e setenta trouxe às Universidades mais "filhos da burguesia". Muitos deles provinham de estratos médios da sociedade portuguesa que começavam a experimentar algum conforto material e a beneficiar de oportunidades de ascensão social. Gente urbana, de olho na Europa democrática e evoluída, aberta às perspectivas de desenvolvimento do País reclamadas pela corrente liberal e modernizante da ditadura. Sem hesitações, autores há que identificam este grupo social 
de fronteiras incertas com a corrente marcelista e liberal do Estado Novo que tardiamente se afirmou. Mais unânime é a ideia segundo a qual o arcaísmo da Universidade e o seu quotidiano conservador colidiram com as expectativas sociais dos jovens burgueses (Caiado, 1990: 74). A ser assim, ironicamente, terá pertencido à geração nascida durante a Guerra e educada na obediência reverente às instituições e dogmas do Estado Novo a transformação da Universidade em território de dissidência social e política.

\section{A inversão sindical do movimento estudantil na abertura dos anos sessenta}

Nem todos os grupos e grupúsculos estudantis se entregaram a estratégias de resistência. Sabendo quão provável e severa seria a repressão governamental contra esse modo de oposição, só a estrutura organizativa do PCP as adoptou no propósito primordial de, em cenários de conflito aberto ou latente, obrigar o regime salazarista a mostrar o seu carácter repressivo.

O posicionamento diferenciado dos sectores da opinião académica durante a "crise estudantil" de 1961-62 permite elucidar os limites das estratégias estudantis de resistência. De forma esquemática e salvo as diferenças entre os movimentos de Lisboa e de Coimbra, podemos desenhar um triângulo: 1) As esquerdas, uma maioria de posição reivindicativa, pró-associativa e disposta a práticas de conotação sindicalista;2) Os católicos da JUC e do CADC, com notórias diferenças entre si e dentro de si (embora convergentes na defesa de um associativismo estudantil plural e contrário a lógicas de representação unívoca por parte das associações de estudantes, por isso anti-sindical); 3) As direitas, um grupo heterogéneo composto por alguns católicos anti-associativos e por uma minoria neofascista e violenta cujo propósito seria eliminar as associações de estudantes (caso do Movimento Jovem Portugal em Coimbra). ${ }^{20}$

Para as oposições políticas à ditadura de Salazar, as sucessivas crises do regime após a Segunda Guerra Mundial - a queda do "fascismo internacional" em 1945, as campanhas eleitorais dos generais Norton de Matos e Humberto Delgado, em 1949 e 1958, respectivamente, o começo da guerra nas colónias em 1961 e as abortadas conspirações militares que ocorreram entre 1946 e 1962 - geraram grandes esperanças e grandes medos. Apesar dos entusiasmos e das ingénuas expectativas, como notou Hermínio Martins, essas crises recorrentes criaram uma espécie de “arma-

${ }^{20}$ Propusemos esta classificação a partir da análise do discurso e das práticas dos movimentos estudantis de 1961-62 no nosso livro sobre o tema (Garrido, 1996: 168-182). Para um exame mais centrado nos acontecimentos de Lisboa, cf. o esquema de classificação proposto por Nuno Caiado (1990: 81-111). 
dilha da iminência para a oposição, inibindo a política do grande arrastamento e o investimento de recursos da oposição numa estratégia de resistência" (1998: 61).

Manobrando em condições muito singulares e ciclos de vida efémeros, a "oposição estudantil" manteve durante boa parte do tempo vínculos irregulares com as oposições políticas. Sobretudo com os sectores comunistas mais empenhados numa assumida estratégia de resistência, visto que tal opção implicaria um difícil compromisso com um conflito prolongado e de desfecho incerto. Ao ritmo das estratégias associativas e perante a inevitabilidade de se recompor sempre que, finda mais uma "crise", a repressão fragmentava os comandos do movimento e ameaçava os demais de prisão e de incorporação militar nas "guerras ultramarinas", o movimento estudantil evoluiu em espirais, viveu de fluxos e refluxos, fez-se de euforias e desânimos. Nem sempre unido e actuando num plano mais ou menos "frentista", as associações de estudantes e as retaguardas informais que delas se formavam sempre que a repressão governamental dissolvia as direcções e suspendia as assembleias magnas mantinham apreciáveis dinâmicas de mobilização para a acção colectiva de sentido político e oposicionista.

Embora esvaziadas de acção política - por imposição estatutária as AE deviam ser apolíticas -, as estruturas associativas, quer em Coimbra, quer em Lisboa e no Porto, eram territórios infra-políticos. ${ }^{21}$ Gozando de uma autonomia inerente, as $\mathrm{AE}$ eram espaços insulares de vida democrática. Eram lugares de vivência cívica cuja representatividade de natureza sindical se reforçava através da defesa de valores intrínsecos sem expressão política evidente: os princípios da autonomia associativa, a própria autonomia universitária e a co-gestão da Universidade.

Não menos relevante foi o uso contestatário do tradicionalismo coimbrão; a inversão da praxe e dos rituais académicos em instrumento de socialização associativa. No caso de Coimbra foi muito importante o efeito de abrigo dos organismos tradicionais da Academia, do "Conselho das Repúblicas" e, em menor escala, do "Conselho de Veteranos".

Se 1956 e 1958 foram momentos capitais nesta transição cultural e política, tal viragem consumou-se em Maio de 1960 com a vitória de uma lista de "esquerda" proposta pelo Conselho de Repúblicas nas eleições para a Associação Académica de Coimbra. No mesmo ano em que Carlos Candal conquistou a Académica às forças da "situação", em Lisboa também

\footnotetext{
${ }^{21}$ Sobre o conceito de infrapolitics, sua construção teórica e operacionalidade relativa à natureza da vida política dos grupos sociais subordinados, ver Scott, 1990, em especial, 183-201.
} 
Jorge Sampaio (Direito) e Eurico de Figueiredo (Medicina) viraram à esquerda as suas associações. Numa metáfora arrebatada, Manuel Alegre comparou "a vitória da lista antifascista" em Coimbra a uma "segunda Tomada da Bastilha" (Raposo, 2005: 37).

Acicatado por querelas de moral e política cujas dimensões o próprio regime exacerbou ao considerar insidiosa a ideia de convívio (convívio inter-académico, ou simplesmente entre sexos), o movimento estudantil tomou uma dimensão nacional. Por banal que hoje pareça, a imagem do estudante de Coimbra deixando a sua cidadela, de capa ao ombro, para se juntar a colegas de Lisboa e do Porto e participar em reuniões inter-associativas, ${ }^{22}$ deu aos movimentos estudantis uma dinâmica nova, tendencialmente federativa. Neste turbilhão de transformações, a mudança de mentalidades foi um sedimento importante. Embora censuradas, as páginas da Via Latina encerram múltiplos sinais de abertura e renovação das práticas culturais dos estudantes. O convívio intelectual entre estudantes e intelectuais neo-realistas rasgou horizontes estéticos e políticos. O teatro e a poesia foram as principais expressões de adesão a formas alternativas de expressão. Um bom exemplo reside na evolução do TEUC: sob a batuta de Paulo Quintela, o Teatro dos Estudantes da Universidade de Coimbra quebrou a hegemonia do teatro clássico e vicentino e ousou levar à cena Garcia Lorca e outros "satânicos autores". ${ }^{23}$

Fazendo uso destas armas culturais e da imaginação, as AE manobravam nos limites da legalidade e, tanto quanto possível, convertiam o apolitismo em trunfo. No caso de Coimbra, o facto de os estudantes adquirirem a condição de sócios da AAC logo que se matriculavam na Universidade - preceito que sempre estivera nos Estatutos da Académica - acabou por dar à velha associação um extraordinário poder de representação dos estudantes. Por ingenuidade ou displicência, até ao começo dos anos sessenta o governo ditatorial nunca viu nisso senão a expressão da ideia do "sindicato corporativo de estudantes".

Sucedeu que a força de representação da AAC foi maior do que nunca durante a "primavera que abalou o regime" ${ }^{24}$ a de 1962. Reagindo a estímulos repressivos do Poder - a proibição ministerial de duas reuniões inter-associativas, o I Encontro Nacional de Estudantes (em Coimbra) e o Dia do Estudante (em Lisboa) -, o movimento mostrou uma força e unidade invulgares. Pela primeira vez, fundou os seus avanços reivindi-

\footnotetext{
${ }^{22}$ A imagem também pertence ao testemunho de Manuel Alegre (apud Raposo, 2005: 37).

23 Cf. as memórias de César Oliveira (1993: 24-25).

${ }^{24}$ A expressão dá título a um livro que reúne testemunhos e documentos sobre a "crise académica de 62", com ênfase no movimento de Lisboa (Ferro, 1996).
} 
cativos e conflituais em legitimidades de tipo sindical: a articulação permanente entre os dirigentes associativos e as massas estudantis reunidas em plenários (Lisboa) ou Assembleias Magnas (Coimbra) participados por milhares de estudantes e por intervenções de ambos os sexos. ${ }^{25}$

Perante as evidências do poder de mobilização dos estudantes próassociativos, o Governo de Salazar inverteu a leitura oficiosa dos factos: embora dependentes das autoridades universitárias, as inócuas "organizações circum-escolares" revelaram-se imaginativas no uso das armas que tinham e converteram-se em "subversivos sindicatos de estudantes". ${ }^{26}$ Guiados por lógicas e práticas classistas, longe do são e rígido modelo corporativo...

A fim de estiolar a inventiva representatividade da Associação Académica e da sua Assembleia Magna de estudantes - que o Reitor de então, Guilherme Braga da Cruz, classificou de "tribunal do povo" -, além de outras severas restrições à liberdade associativa destinadas a pôr termo à "crise de 1962", ${ }^{27}$ o Governo impôs à AAC novos Estatutos. A inibição legal de uma representação unívoca dos interesses estudantis (caucionada pelos estatutos velhos) e a prevenção do devir sindical do movimento estudantil foram preocupações primeiras. O Decreto-Lei n ${ }^{\circ} 44$ 632, de 15 de Outubro de 1962, presumia um sentido preventivo de novos movimentos de contestação e confirmava a perspectiva governamental - já presente no "40 900" e em toda a legislação afim promulgada durante a ditadura salazarista - das associações de estudantes como estruturas orgânicas da Universidade. ${ }^{28}$

Segundo esta análise atenta da "crise académica" de 1962, o Decreto-Lei continha diversas subtilezas repressivas. Entre elas, a que fazia depender a criação e o funcionamento das $\mathrm{AE}$ da aprovação dos respectivos estatutos pelo Ministério da Educação Nacional, mediante parecer prévio dos reitores das escolas e da sombria Comissão Permanente das Organizações Circum-Escolares do Ensino Superior (na qual os estudantes continuavam a não ter assento). Uma vez que, à data de publicação do Decreto-Lei, todas as AE se encontravam suspensas, a "reorganização" das mesmas implicava aprovar estatutos ajustados à nova legislação. Os

\footnotetext{
${ }^{25}$ Testemunho de J. Medeiros Ferreira, apud Raposo, 2005: 46.

${ }^{26}$ Expressão comum nas notas oficiosas governamentais.

${ }^{27}$ A 7 de Maio de 1962, por Portaria do Ministério da Educação Nacional, o Governo suspende a DG da AAC e dissolve a Assembleia Magna. No dia 18 de Mai,o é imposta à secção de futebol uma comissão administrativa presidida por um militar. A 27 de Agosto, a PIDE prende em Coimbra umas dezenas de estudantes.

${ }^{28}$ Analisámos os mecanismos de inibição governamental do relançamento da revolta estudantil de 1962 no nosso citado livro (Garrido, 1996: 182-194).
} 
da AAC foram publicados a 13 de Setembro de 1963. Deles desaparecera o princípio da apoliticidade e neles se previam severas limitações da liberdade associativa dos estudantes. A AAC só representaria os sócios que nela estivessem inscritos e a direcção seria eleita na proporção dos votos, processo que, mesmo em caso de derrota, permitiria à "direita estudantil" eleger alguém seu para os corpos gerentes. ${ }^{29}$

Em rigor, a "crise de 1962" nunca terá sido ostensivamente sindicalista. É certo que os discursos e as práticas mais comuns do movimento foram muito chegados a certos tópicos do catecismo sindicalista definido para o associativismo estudantil francês e europeu na Carta de Grenoble de $1946 .{ }^{30}$ A principal novidade da "Carta" - assim a designavam os dirigentes mais empenhados no contacto de ideias e experiências com os dirigentes estrangeiros - era a definição do estudante como "jovem trabalhador intelectual”. Assentando neste postulado de conotação marxista, os adeptos do sindicalismo reivindicavam a transformação das condições intelectuais do "trabalho estudantil" de modo a que a Universidade não mais se apartasse da vida económica e social dos Estados-Nação e do próprio mundo. A Carta de Grenoble apelava ao comprometimento social do estudante, exaltava-o como fracção activa da sociedade num plano equivalente ao do operário. Fazia-o num plano tão similar ao dos trabalhadores que a UNEF (União Nacional dos Estudantes Franceses) chegou a reclamar o direito dos estudantes a um "pré-salário" atribuído pelo Estado.

Estabelecida em função do valor do trabalho (e do trabalho como valor), acreditava-se que a consciencialização das massas estudantis reforçaria sentimentos de pertença a uma condição juvenil subordinada, mas dotada de reais poderes reivindicativos. A influência deste discurso e do modelo sindical francês sobre o movimento estudantil que deflagrou em Portugal no começo da década de sessenta foi clara, mas restrita. Conheciam-na alguns dirigentes, nomeadamente através da "secção de intercâmbio" da AAC. À maioria dos estudantes das universidades de Coimbra, de Lisboa e do Porto, as teses do sindicalismo estudantil chegaram em diferido e sem influência marcante na acção colectiva. Axioma elitista e difícil de apregoar numa Universidade ainda a braços com o elementar problema das liberdades públicas e do respeito pela autonomia de associação, a definição do estudante como "jovem trabalhador intelectual" esbarrou na mentalidade "corporativa" das populações estudantis. Ora

${ }^{29}$ Cf. Estatutos da Associação Académica de Coimbra. Lisboa, Imprensa Nacional, 1963.

${ }^{30}$ Sobre a Carta de Grenoble e os contextos em que surgiu, cf. Gaudez, 1965. 
por pedantismo, ora por simples ironia ou fanfarronice, alguns dirigentes apresentavam-se a seus pares como "jovens trabalhadores intelectuais". Se o fizessem fora dos corredores das associações, seria certo que ninguém os compreenderia.

Mesmo perante estes limites, por toda a década de sessenta o movimento estudantil português terá sido dominado pela "ideia sindical". Embora pouco patrimonializada durante a grande "crise de 1969", a memória de 1962 deixou heranças indeléveis (Estanque e Bebiano, 2007: 169-176). Nunca como então os estudantes da Universidade salazarista haviam adoptado práticas reivindicativas identificáveis com o modelo sindical. ${ }^{31} \mathrm{O}$ recurso a formas de contestação típicas do mundo do trabalho (greves) e a reclamação de interesses comuns às condições estudantil e juvenil, fundindo uma e outra numa categoria social subordinada, sinalizaram importantes transformações no discurso e nas práticas. O carácter federativo de diversas acções de protesto e a recusa da colaboração docente para a resolução de problemas tidos como próprios dos estudantes foram, também, relativas novidades. A principal transformação terá sido, porém, o abalo político gerado pela greve de 1962, causa e efeito de uma mais larga e sentida compreensão de que as liberdades implicavam práticas e compromissos de resistência.

\section{Conclusão}

As representações sociais dominantes sobre a juventude universitária assentam num binómio redutor cujas raízes parecem alimentadas pela memória histórica das lutas estudantis dos anos sessenta do século XX. À juventude "militante", "utópica" e solidária dos anos sessenta e setenta, a opinião dominante contrapõe a juventude "céptica”, "pragmática", "individualista" e hedonista dos nossos dias..$^{32}$ Dada a "democratização do acesso" ao Ensino Superior, que tornou muito mais expressiva a porção de jovens que hoje vivem tal idade e condição social dentro da Universidade, essa representação dual tornou-se comum.

Nenhuma das imagens será rigorosa. Ambas parecem excessivas e baseadas numa peleja geracional que supõe o julgamento das diferenças e das alegadas inconsistências do associativismo estudantil, bem como dos comportamentos juvenis dos dias de hoje, tempos de desencantada democracia.

\footnotetext{
${ }^{31}$ Desenvolvemos esta abordagem em Garrido, 1996: 158 ss.

${ }^{32}$ Para um exame relativamente actualizado destas representações, cf. José Machado Pais, 1993: 26 ss.
} 
Como lembrou António Sérgio, "a educação é a arte de emancipar os homens". Ou, indo mais além no apelo, "não devemos educar a juventude para esta sociedade do nosso tempo, mas para uma sociedade melhor, possível no futuro" (Sérgio, 1957: 9). Temos dúvidas de que seja este o "programa de Bolonha”, tão despido que está de utopias, que não a da perfomance institucional da "qualidade". Ou tão pouco o de outras compulsivas reformas que prometem devolver à Universidade aquilo que ela nunca pôde ser.

Como sugeriu Readings, na Universidade pós-moderna - que parece ser aquela em que vivemos - o mito tecno-burocrático da "excelência" desabitou-a como lugar de cultura e de pensamento (2003: 16, 22, 189-201). A forma aparentemente unânime - e aparentemente acrítica - como estudantes e professores têm participado destes discursos legitimadores e dos apelos a uma indefinida modernização da Universidade faz supor que a crise da velha instituição é autêntica e tão funda como o foi em momentos passados. ${ }^{33}$

Se o frentismo sindical das revoltas estudantis dos anos sessenta acusou a Universidade de instituição conservadora e burocrática, reprodutora de uma ordem social contrária à vivência juvenil - sentidos que se entranharam na sociedade, quais indiscutíveis rótulos -, resta saber qual será o significado das transformações que a Universidade actual acabará por gerar para disfarçar ou resolver os novos impasses com que se debate.

Ontem como hoje, é de crer que o poder da imaginação volte a gerar soluções transformadoras. É de esperar que o associativismo estudantil se reinvente e que alguns dóceis funcionários do sistema (professores e investigadores) se rebelem contra a retórica hiper-funcional e "produtivista" que os constrange na apertada condição de colaboradores de erráticas agendas "transnacionais" de investigação.

\section{Referências bibliográficas}

Bebiano, Rui (2003), O poder da imaginação. Coimbra: Angelus Novus.

Bourdieu, Pierre; Passeron, Jean-Claude (1978), A reprodução: elementos para uma teoria do sistema de ensino. Lisboa: Vega.

Caiado, Nuno (1990), Movimentos estudantis em Portugal: 1945-1980. Lisboa: IED. Cardina, Miguel (2008), A tradição da contestação. Resistência estudantil em Coimbra no Marcelismo. Coimbra: Angelus Novus.

${ }_{33}$ Para uma fecunda e recente reflexão sobre os sentidos da "crise da Universidade" actual, cf. Torgal, 2008. 
Carreras Ares, Juan J. (1991), “Los fascismos y la Universidad”, in J. J. Carreras Ares; Miguel Ángel Ruiz Carnicer (orgs.), La Universidad Española bajo el régimen de Franco (1939-1975). Zaragoza: Institución Fernando El Católico.

Comissão do Livro Negro sobre o Regime Fascista (1983), Os estudantes no regime fascista. $1^{\mathrm{o}}$ vol. Lisboa: Presidência do Conselho de Ministros.

Cruzeiro, Celso (1989), Coimbra, 1969. Porto: Afrontamento.

Estanque, Elísio; Bebiano, Rui (2007), Do activismo à indiferença. Movimentos estudantis em Coimbra. Lisboa: Imprensa de Ciências Sociais.

Faria, Cristina (1998), As lutas estudantis na Ditadura Militar (1926-1932). Lisboa: Universidade Nova de Lisboa (diss. de Mestrado em História Contemporânea).

Ferro, João Pedro (1996), A Primavera que abalou o regime. A crise académica de 1962. Lisboa: Presença.

Fontes, Paulo (1991), "As organizações estudantis católicas e a crise académica de 1956/57”, in Actas: Universidade(s). História, memória, perspectivas. Vol. 5. Coimbra: Universidade de Coimbra, 457-480.

Garrido, Álvaro (1995), "Crise académica de Coimbra/62: a ideia de sindicalismo estudantil”, História, XVII(11-12), 32-41.

Garrido, Álvaro (1996), Movimento estudantil e crise do Estado Novo. Coimbra: Minerva.

Garrido, Álvaro (1998), "Universidade e Juventude: da reprodução à contestação", in Maria Cândida Proença (org.), O sistema de ensino em Portugal, séculos XIX-XX. Lisboa: Colibri/IHC da FCSH da Universidade Nova de Lisboa, 161-174.

Gaudez, Pierre (1965), Os estudantes. Trad. Vasco Pulido Valente. Lisboa: Moraes.

Grácio, Rui (1989), "Moral e política na Academia de Coimbra, crónica documental de uma polémica no dealbar dos anos sessenta”, Vértice, II série, 15.

Lopes, Pedro S. (1992), "Coimbra, tradição e desporto nos anos 50 - A questão do 40 900”, in Luís Reis Torgal (org.), Ideologia, cultura e mentalidade no Estado Novo. Coimbra: FLUC, 170-189.

Martins, Hermínio (1998), Classe, status e poder. Lisboa: ICS.

Moreira, Adriano (2000), "Universidades”, in António Barreto; Maria Filomena Mónica (orgs.), Dicionário de História de Portugal, vol. IX (Suplemento). Porto: Figueirinhas, 569-574.

Nunes, Adérito Sedas (2000), Antologia sociológica. Selecção e prefácio de Maria Filomena Mónica. Lisboa: ICS.

Oliveira, César (1993), Os anos decisivos, Portugal 1962-1985 - Um testemunho. Lisboa: Presença.

Pacheco, Fernando Assis (1993), Trabalhos e paixões de Benito Prada. Lisboa: Asa.

Pais, José Machado (1993), Culturas Juvenis. Lisboa: INCM.

Raposo, Eduardo (2005), Canto de intervenção, 1960-1974. Lisboa: Público.

Readings, Bill (2003), A Universidade em ruínas. Coimbra: Angelus Novus. 
Scott, James C. (1990), Domination and the Arts of Resistance. New Haven/London: Yale University Press.

Sérgio, António (1957), Antologia sociológica. $7^{\circ}$ caderno. Lisboa: ed. do autor.

Torgal, Luís Reis (1991), “A Universidade, a ditadura e o Estado Novo (1926-1961):

Notas de uma investigação colectiva”, in Actas: Universidade(s). História, memória, perspectivas. Vol. 5. Coimbra: Universidade de Coimbra, 401-430.

Torgal, Luís Reis (1999), A Universidade e o Estado Novo. Coimbra: Minerva.

Torgal, Luís Reis (2000), "Universidade de Coimbra”, in António Barreto; Maria Filomena Mónica (orgs.), Dicionário de História de Portugal, vol. IX (Suplemento). Porto: Figueirinhas.

Torgal, Luís Reis (2008), A Universidade e as "condições" da imaginação. Coimbra: Centro de Estudos Interdisciplinares do Século XX.

Vilaça, Alberto (1998), O MUD Juvenil em Coimbra. História e estórias. Porto: Campo das Letras. 